\title{
Host immune response to infection with porcine circoviruses
}

\author{
Ruihan Shi', Lei Hou, ${ }^{2,3}$ and Jue Liư ${ }^{2,3^{*}}$
}

\begin{abstract}
Porcine circovirus type 2 (PCV2), which serves as a major causative agent of PCV2-associated diseases and causes severe loss to the pig industry worldwide, can dysregulate the immune response and induce immunosuppression in PCV2-infected pigs. Similar to PCV2, porcine circovirus type 3 (PCV3), a newly identified swine circovirus which might be closely associated with porcine dermatitis and nephropathy syndrome, reproductive disorder, and multisystemic inflammatory responses, also interferes with host immune defense. Interaction between host immune system and PCVs is considered to be a crucial determinant of pathogenicity in pigs. Here, we sought to briefly discuss the current knowledge regarding the interaction of porcine circovirus type 2 and/or 3 with host immune cells and immune responses to better depict the viral immunomodulatory capacity, pathogenic mechanisms, and the future research direction in host immune responses to infection with PCV2 and PCV3.
\end{abstract}

Keywords: Porcine circovirus (PCV), Porcine circovirus-associated disease, Lymphoid depletion, Immune responses, Pathogenesis

\section{Background}

Porcine circovirus (PCV), a small non-enveloped virus with a single-stranded circular DNA genome, belongs to the Circoviridae family (Ellis 2014). Porcine circovirus type 1 (PCV1) is nonpathogenic to pigs; however, porcine circovirus type 2 (PCV2) is a major causative agent of postweaning multisystemic wasting syndrome (PMWS) (Ellis et al. 1998; Harding et al. 1998), now referred to as PCV2-associated disease (PCVAD) (Segalés et al. 2005; Opriessnig et al. 2007). PCVAD is associated with progressive weight loss, congenital tremors, respiratory and enteric diseases, dermatitis, nephropathy, reproductive failures, etc. Currently, PCVAD is an important disease in all swine-rearing countries and regions of the

\footnotetext{
* Correspondence: liujue@yzu.edu.cn

${ }^{2}$ Department of Preventive Veterinary Medicine, College of Veterinary Medicine, Yangzhou University, No. 48 Wenhui Road, Hanjiang District, Yangzhou 225009, China

${ }^{3}$ Jiangsu Co-Innovation Center for Prevention and Control of Important Animal Infectious Diseases and Zoonoses, Yangzhou University, Yangzhou 225009, China

Full list of author information is available at the end of the article
}

world and is now threatening the healthy development of the global pig industry.

The clinical symptoms of PCVAD include weight loss, anemia, jaundice, enlarged lymph nodes, diarrhea and dyspnea (Ramamoorthy and Meng 2009). PCV2 has the strongest tropism for lymphoid tissues. Lymphoid depletion and histocyte infiltration in lymphoid tissues were determined to be hallmark pathologic lesions of PCVAD (Chae 2004; Opriessnig et al. 2007; Ramamoorthy and Meng 2009; Meng 2013). Although PCV2 has been recognized as the primary etiological agent for PCVAD, attempts to reproduce the disease in gnotobiotic pigs via PCV2 infection alone have failed (Krakowka et al. 2000, 2001, 2008). Further, in field cases, only a proportion of the infected pigs eventually developed the typical symptoms (Meng 2013). These findings imply that PCV2 is necessary but insufficient to trigger PCVAD. Co-infections with agents, such as porcine reproductive and respiratory syndrome virus (PRRSV), porcine pseudorabies virus (PRV), porcine parvovirus (PPV), septic bacteria, mycoplasma hyopneumoniae, or

(c) The Author(s). 2021 Open Access This article is licensed under a Creative Commons Attribution 4.0 International License, which permits use, sharing, adaptation, distribution and reproduction in any medium or format, as long as you give appropriate credit to the original author(s) and the source, provide a link to the Creative Commons licence, and indicate if changes were made. The images or other third party material in this article are included in the article's Creative Commons licence, unless indicated otherwise in a credit line to the material. If material is not included in the article's Creative Commons licence and your intended use is not permitted by statutory regulation or exceeds the permitted use, you will need to obtain permission directly from the copyright holder. To view a copy of this licence, visit http://creativecommons.org/licenses/by/4.0/. The Creative Commons Public Domain Dedication waiver (http://creativecommons.org/publicdomain/zero/1.0/) applies to the data made available in this article, unless otherwise stated in a credit line to the data. 
immunostimulation induced by particular vaccination or adjuvant were demonstrated to serve as additional triggering factors for PCVAD (Pallares et al. 2002; Meng 2013; Dorr et al. 2007; Opriessnig and Halbur 2012). Experiment models showed that PCV2 replication can be augmented by co-infection with other viruses or bacteria, but the exact mechanisms remain unknown. It is speculated that the initiation of the host cellular mitosis induced by co-pathogen infections facilitates new cellular DNA synthesis which serves as the only prerequisite for PCV2 replication (Opriessnig and Halbur 2012). It is also suggested that concurrent infections of PCV2 with other pathogens interfere with cytokine responses which may affect PCV2 clearance and thus favor the viral persistence (Opriessnig and Halbur 2012). The interactions between PCV2/other pathogens and host responses in concurrent/secondary infection cases play a significant role in the pathogenesis and warrant further research. PCVAD-affected pigs have been recognized to be immunocompromised. PCV2 can infect and replicate in lymphoid tissues, such as lymph nodes, thymus, tonsils and spleen, thereby destroying lymphoid follicle architecture and resulting in leucopenia and immunosuppression (Darwich et al. 2002; Ramamoorthy and Meng 2009; Darwich and Mateu 2012; Meng 2013). The involvement of immune cells and immune response in PCV2 infection has been suggested to be crucial for PCVAD development.

In 2015, porcine circovirus type 3 (PCV3) was first identified in PCV2-negative sows that clinically manifested porcine dermatitis and nephropathy syndrome (PDNS), reproductive failure, and acute death in the US (Palinski et al. 2016). Pathological lesions and the viral antigen were determined in multiple tissues and organs including lung, liver, spleen, kidney, heart, lymph nodes, and intestines (Jiang et al. 2019a). Interestingly, research showed that PCV3 was also detectable in fecal samples, suggesting a fecal-oral transmission manner (Zhai et al. 2017). To date, PCV3 has been reported to circulate with widely geographical distribution in the world (Fan et al. 2016; Shen et al. 2017; Zhai et al. 2017). PCV3 genome is larger than PCV2 and the amino acid sequence in Cap proteins of both viruses displayed only a 36-37\% similarity (Morozov et al. 1998; Palinski et al. 2016). Previous studies suggested that some of glycosaminoglycans functioned as the cellular surface receptors for PCV2 (Misinzo et al. 2006); however, the specific motif recognized by the receptors is not present in the cap of PCV3 (Shi et al. 2021).

PCV3 antigen was demonstrated to colocalize with the typical PDNS histopathological lesions. According to retrospective studies conducted by Palinski et al., a 93.8\% positive rate was found for PCV3 infection in PCV2-negative cases with PDNS features (Palinski et al.
2016). Research also reported an abnormally high positive rate $(85.7 \%)$ for PCV3 infection in pigs with productive failure in the absence of PCV2, PRRSV or PRV (Fan et al. 2016). In contrast to PCV2 (Allan et al. 1999; Allan et al. 2000; Ha et al. 2008; Krakowka et al. 2008), attempts to experimentally reproduce PDNS with PCV3 alone was successful (Jiang et al. 2019a). Owing to these findings, an etiologic role has been assigned to PCV3 in PDNS. Immune tissue injuries were also notably observed in pigs infected with PCV3. These injuries were mainly characterized as lymphocytic necrosis and depletion, histiocytes and multinucleated giant cell replacement, and interestingly, an infiltration of eosinophils (Palinski et al. 2016; Jiang et al. 2019a). Currently, PCV3 has been detected in many countries and has emerged as a potential pathogenic threat to the global pig industry (Chung et al. 2021; Tochetto et al. 2020), thereby emphasizing the necessity to reveal the pathogenesis of PCV3 infection. This review sought to briefly describe the interactions of PCV2 and PCV3 with host immune system, which may enable us to gain a better understanding of their viral immunomodulatory capacity and pathogenic mechanisms.

\section{Lymphoid depletion caused by PCV2 infection}

Lymphoid depletion followed by histiocytic replacement has been recognized as the most remarkable pathological feature of PCVAD (Chae 2004; Opriessnig et al. 2007; Ramamoorthy and Meng 2009; Meng 2013). The development of lymphoid depletion is positively associated with the level of viral antigen in infected tissues (Darwich and Mateu 2012; Meng 2013). Lymphopenia induced by PCV2 infection is mainly characterized by loss of $\mathrm{T}$ and $\mathrm{B}$ lymphocytes, dendritic cells (DCs), and natural killer cells (Darwich et al. 2002; Nielsen et al. 2003; Grierson et al. 2007; Darwich and Mateu 2012). Further, the proportion of neutrophils and monocytes is increased in this diseased state (Darwich et al. 2003b; Sipos et al. 2004).

The necrosis and lysis of lymphoid cells caused by direct viral infection and replication are suggested to play important roles in lymphoid depletion mechanisms of PCVAD (Meng 2013). Uncontrolled inflammation followed by extravasation of histiocytes to inflammatory sites largely contributes to lymphoid tissue damage (Shibahara et al. 2000). Cell apoptosis and lymphoid proliferation failure may also account for immune injury caused by PCV2 infection. A protein encoded by PCV ORF3 can induce apoptosis by activating caspase- 3 and caspase-8 signal pathways in PK15 cells (Liu et al. 2005). Further, B lymphocyte depletion due to PCV2-mediated apoptosis is as well as the apoptosis of macrophages induced by PCV2 infection have been identified (Shibahara et al. 2000). Histiocyte apoptosis in the germinal centers 
of lymphoid tissues was also observed in PCV2-infected mice (Kiupel et al. 2001). However, some published studies argued the primary role of PCV2-mediated apoptosis in lymphoid depletion or lymphadenopathy, suggesting that the rate of apoptosis is negatively correlated with viral load in tissues (Resendes et al. 2004). As the proliferation and recruitment of lymphocytes from blood are attributed to the maintenance of cell mass in lymphoid tissues, a decrease in cell proliferation rather than apoptosis has been proposed to be responsible for lymphoid depletion observed with spontaneous PCV2 infections.

PCV2 infection can activate autophagy and subsequently enhance viral multiplication through AMPK/ ERK/TSC2/mTOR signaling pathway in PK15 cells (Zhu et al. 2012; Ren et al. 2016). However, whether autophagy occurs in immune cells or participates in host lymphoid depletion remains unresolved. Immune suppression is mainly related to lymphoid depletion in PCV2-infected pigs, and the exact determinants and mechanisms of lymphoid depletion remain to be elucidated and warrant further research.

\section{Interaction between PCV2 and dendritic cells}

PMWS was previously identified as the most serious disease type of PCVAD. PMWS affects 5- to 12-week-old pigs and has a high fatality rate in nursing and fattening pigs. It is characterized by weight loss, dyspnea and generalized lymphadenectasis (Chae 2004). Based on microscopic analysis, PMWS is typically characterized by lymphoid depletion, histiocytic infiltration, and granulomatous inflammation in lymphoid organs. PCV2 inclusion bodies were observed in histiocytes, including macrophages within the injured organs from PMWSaffected pigs (Rosell et al. 1999; Chae 2004). PCV2 antigen-positive cells with "dendritic cell-like" morphology have also been identified (Rosell et al. 1999; Vincent et al. 2003).

As the primary immune cells and one of the key antigen-presenting cells in host immune system, dendritic cells (DCs) play an essential role in regulating innate immune reactions, initiating adaptive immune responses, coordinating the crosstalk of both, and contributing to the maintenance of self-tolerance. As the sentinels, DCs present within skin and mucosa participate in formation of the first line of immune defense against viral invasion (Mellman and Steinman 2001; Geissmann et al. 2010). Most DCs (80-90\%) can interact with PCV2, and both monocyte-derived DCs (MoDCs) and bone marrow-derived DCs (BMDCs) are susceptible to PCV2 in vitro. The infectivity of PCV2 was found to be preserved in cells for at least 5 days without detectable viral replication or degradation (Vincent et al. 2003). Further, co-culture of PCV2-carrying MoDCs with syngeneic $\mathrm{T}$ lymphocytes did not induce virus transmission to lymphocytes or impair their cellular viability (Vincent et al. 2003, 2005), which suggests that lymphoid tissue injury may not be attributed to the direct interaction between infected-DCs and the lymphocytes. The internalization of PCV2 into DCs neither stimulates nor inhibits cell differentiation. The ability to process and present antigens, such as superantigen, staphylococcal enterotoxin B, by DCs was not impaired by PCV2 infection (Vincent et al. 2003). Such uptake of PCV2 into DCs is thus an active process that occurs via phagocytosis or endocytosis for PCV2 internalization in DCs rather than a passive infecting process. The seemingly abortive and silent PCV2 infection in DCs not only shelters virus from host immune attack, but also makes the cell an ideal "trojan horse" for viral spread via DCs migratory activity throughout the host.

Although DCs do not support apparent PCV2 replication, PCV2 infection markedly affects functions of DCs and associating host immune defense in many aspects. Co-stimulating molecules of DCs play an important role in T lymphocyte activation. In vitro, expression levels of MHC I, MHC II, CD80/86, CD25, CD16, or CD14 on DCs were not apparently altered by PCV2 persistent infection (Gilpin et al. 2003; Vincent et al. 2003, 2005); however, in vivo, PCV2 infection was demonstrated to downregulate the expression of surface co-stimulatory molecules, including CD40, CD86 and CD137 (Wang et al. 2017). Moreover, PCV2-infected porcine iliac artery endothelial cells reduced MoDC adhesion and migration ability, thereby hampering MoDC maturation and inhibiting their antigen presentation ability (Liu et al. 2019). Monocyte chemotactic protein-1 (MCP-1) is responsible for monocytes and memory $\mathrm{T}$ cell recruitment in host immune responses. An absence of MCP-1 production has been observed in spleen CD11c + DCs of PCV2-infected mice (Wang et al. 2017). Furthermore, the coculture of PCV2-carrying DCs with peripheral blood mononuclear cells (PBMCs) in vitro has been observed to markedly induce the CD4 + CD25 + FoxP3 + regulator $\mathrm{T}$ cells, which is known to mediate immunological tolerance in host immune response (Cecere et al. 2012).

Plasmacytoid DCs (pDCs) are major cells producing interferon (IFN) type I. As a result, they are also called natural interferon producing cells (NIPCs). The endosomal TLR9 of NIPC can interact with the cytosinephosphorothioate-guanine-oligodeoxynucleotide (CpGODN) motifs of bacteria and viruses, leading to the secretion of IFN- $\alpha$ and TNF- $\alpha$. IFN- $\alpha$ serves as an important mediating factor for innate and adaptive immune responses by inducing an antiviral state in cells presenting its receptor as well as modulating and activating 
immune cells. Besides, a cocktail of IFN- $\alpha$ and TNF- $\alpha$ was proven to promote both autocrine and paracrine maturation of myeloid DCs (Vincent et al. 2005; Ramamoorthy and Meng 2009). Therefore, NIPCs play a crucial role in triggering host immune defense against pathogens. However, PCV2 DNA was demonstrated to interfere with the reactions of NIPCs to pathogenic CpG-ODNs and hence suppress cytokine production of IFN- $\alpha$ and TNF- $\alpha$ (Vincent et al. 2006). PCV2 DNA was also found to impair the response of NIPCs to TLR7 agonists and other swine viral pathogens, including the porcine pseudorabies virus, classical swine fever virus, and transmissible gastroenteritis virus (Vincent et al. 2006). In addition, PCV2 DNA was demonstrated to affect cytoskeletal rearrangement and endocytic process of pDCs, which are associated with cellular immunomodulatory ability (Balmelli et al. 2015). These findings indicate that PCV2 DNA is an important immunomodulatory factor that can inhibit NIPC function by regulating cytokine release, affect both innate and adaptive immunity, and thereby favoring concurrent or secondary infection, which is proposed to play a significant role in the immune dysfunction mechanism in PCV2-infected pigs and contribute to the development of PCVAD (Fig. 1).
A defensive measure was also taken by DCs to resist PCV2 infection. IL-12 plays an essential role in host innate immune defense against viral invasion and is also responsible for mediating adaptive immune response by promoting Th1 cell differentiation. IL-12 production in BMDCs is significantly increased in response to the whole PCV2 particles or virus-like particles (VLPs) stimulation, but not the PCV2 DNA sequences (Kekarainen et al. 2008a), which may assist in immune protection induced by VLPs inoculation.

PCV2 is internalized by both mature and immature DCs, which may exclude the role of macropinocytosis pathway in viral entry (Vincent et al. 2005). Clathrin is proposed to participate in PCV2 entry into DCs as the internalization process is sensitive to chlorpromazine treatment (Vincent et al. 2005). This is similar to simian immunodeficiency virus uptake by DCs, which employs a clathrin-dependent endocytic entry pathway and is related to the persistence observed in human immunodeficiency virus-1 (HIV-1) infection (Ploegh 1998; Frank et al. 2002; Vincent et al. 2005). Silent and persistent infection of PCV2 in DCs and the cellular immunomodulatory ability would be the viral evolutionary advances. Interactions between virus and DCs have significant consequences on host immune responses. The role of DCs

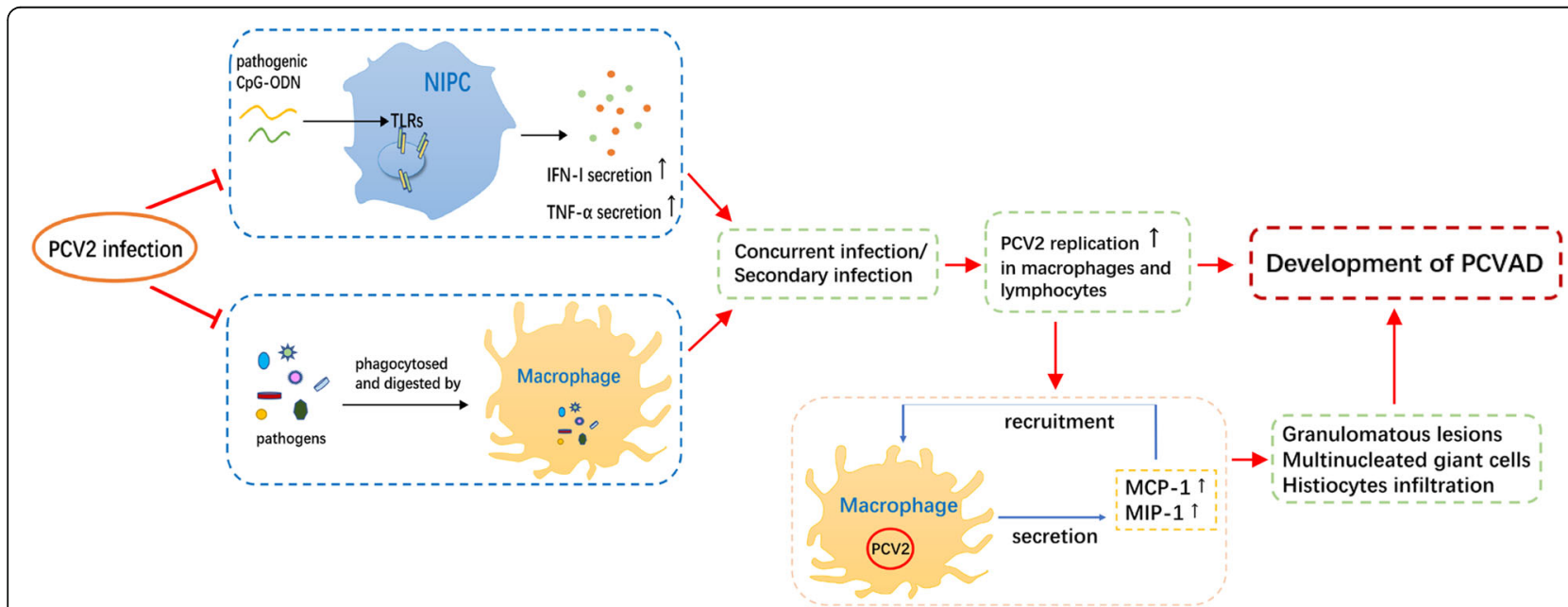

Fig. 1 Speculated involvement of natural interferon producing cells (NIPCs) and monocytes/macrophages in the pathogenesis of PCVAD induced by co-infection with PCV2 and other pathogens. PCV2 DNA has been reported to interfere with the response of NIPCs to pathogenic cytosinephosphorothioate-guanine-oligodeoxynucleotides (CpG-ODNs) and hence suppress the production of IFN- $a$ and TNF- $a$. On the other hand, PCV2 infection impairs the phagocytic and microbicidal ability of macrophages. These findings indicate that interactions of PCV2 with NIPCs and macrophages render host more susceptible to concurrent or secondary infection. Considering that the replication of PCV2 in macrophages is proposed to be achievable in vitro using appropriate stimulatory signals (such as the liposaccharide signal) and that it leads to the accumulation of the viral antigen, it can be speculated that immune stimulation by infection or vaccination promotes PCV2 replication in lymphoid tissues, which may provide a good explanation of PCVAD development following co-infection of PCV2 with other viral or bacterial pathogens rather than by PCV2 infection alone. In addition, interaction of monocyte/macrophage cell lineages with PCV2 plays an important role in mediating granulomatous lesions in lymph nodes and inducing PCVAD. Macrophages are recognized to be the primary cell source of MCP-1 and MIP-1, and it is suggested that MCP-1 and MIP-1 expression could be directly induced by PCV2 infection. Given that MCP-1 and MIP-1 have effective chemoattractant and activating effects on monocytes, high levels of both were speculated to largely facilitate the recruitment of monocytes from blood. The greater number of monocytes recruited to lymphoid tissues can in turn further augment and amplify cytokine secretion and cell recruitment, subsequently inducing granulomatous inflammation and leading to PCVAD 
in PCV2 infection and PCVAD may be an important part in host immune dysfunction and warrants further investigation.

\section{Interaction between PCV2 and monocyte/macrophage}

Besides DCs, monocytes and macrophages are major cells in the innate immune system. Monocytes and macrophages are professional phagocytic cells that originate from common myeloid progenitor cells and take responsibility for processing and presenting antigens, eliminating pathogens and foreign bodies, secreting inflammatory cytokines, as well as activating adaptive immune response. In PCV2-infected pigs, the viral antigen and DNA are present in cells with a monocytic cell morphology, and inclusion bodies containing PCV2 antigen are visualized in macrophages located in the lesion area (Rosell et al. 1999; Kim et al. 2003; Vincent et al. 2003), thereby indicating that monocytes may play a role in PCV2 infection and PCVAD.

According to an in vitro study by Gilpin et al. (Gilpin et al. 2003), viral antigen was persistently detected in the cytoplasm of both monocytes and macrophages infected with PCV2 without any apparent increase in viral progeny. Besides, viral antigen and nucleic acid have been observed only in the cytoplasmic area but not the intranuclear area in isolated alveolar macrophages inoculated with PCV2, which implicated a phagocytosis or endocytosis entry pathway for PCV2 (Chang et al. 2006a). These findings suggest that monocyte/macrophage lineage cells are not the primary site for supporting PCV2 proliferation. Similar to the infection of DCs, PCV2 in phagocytic cells appears to be caused by merely internalization of other infected cells or viral particles by engulfing, or preparation for antigen presenting. Likewise, lymphocytes are also proposed not to be the primary site that supports PCV2 replication (Rosell et al. 1999; Allan and Ellis 2000; Gilpin et al. 2003). However, PCV2 replication measured by spliced cap mRNA and viral DNA was determined in $\mathrm{T}$ and $\mathrm{B}$ lymphocytes as well as monocytes isolated from PBMCs and bronchial lymph nodes in infected pigs. According to the research, all cell lineages support PCV2 replication in vivo (Yu et al. 2007a). More importantly, replication of PCV2 in macrophages is proposed to be achievable in vitro with the trigger of appropriate stimulatory signals, such as LPS (Chang et al. 2006b), thereby leading to viral antigen accumulation. Combined with previous findings that PCV2 infection impairs phagocytic and microbicidal ability of macrophages and thus favors co-infection (Chang et al. 2006a, 2006b), it may also provide a good explanation for PCVAD development by concurrent infection or secondary infection of PCV2 with other viral and bacterial pathogens rather than PCV2 infection alone. Interestingly, the in vitro findings also revealed that lymphocytes support PCV2 replication under ConA stimulation (Yu et al. 2007b). Therefore, immune stimulation by pathogen or vaccination was proposed to promote PCV2 replication in lymphoid tissues, probably in monocytes/macrophages and the lymphocyte, which may largely contribute to the pathogenic mechanisms of PCVAD (Fig. 1).

Porcine alveolar macrophages (PAMs) are the main target cells of PCV2 infection in PMWS-affected pigs (Li et al. 2013). PCV2 replication was not observed in PAMs in vitro (Gilpin et al. 2003; Meerts et al. 2005b), whereas in vivo findings revealed that PCV2 cap mRNA is present in bronchoalveolar lavage (BAL) cells-more than $90 \%$ of which consist of PAMs-from pigs intranasally inoculated with PCV2 as early as 3 days post infection ( $\mathrm{Yu}$ et al. 2007a). Such findings suggest that PAMs may serve as important sites for PCV2 replication in vivo. Host signaling molecules associated with inflammation have been found to be upregulated in isolated PAMs inoculated with PCV2 in vitro, which results in persistent cytokine production and may account for the systematic inflammation of PMWS. Expression of TNF- $\alpha$, granulocyte colony-stimulating factor, and IL-8 is reported to be upregulated by PCV2 infection in PAMs (Chang et al. 2006a, 2006b). Some of these cytokine profile changes in PAMs due to PCV2 may affect local pulmonary functions and defense, and result in tissue lesions. Besides lymphoid depletion, granulomatous lesions, which are characterized by histiocyte proliferation along with epithelioid macrophages and multinucleated giant cell infiltration, were also identified as particular markers of lymph node injury in PCVAD-affected pigs (Opriessnig et al. 2006; Meng 2013). The macrophages in the granuloma area, mainly derived from blood monocytes and locally proliferating histiocytes, can be transformed into epithelioid cells and multinucleated giant cells with a specific morphology. The presence of PCV2 viral inclusion bodies as well as the hybridization signals for MCP1 and macrophage inflammatory protein-1 (MIP-1) were detected in epithelioid macrophages. Further, multinucleated giant cells were strictly located in the granulomatous inflammatory area (Kim and Chae 2004). Macrophages are recognized to be the primary cell source of MCP-1 and MIP-1, and expression of them is suggested to be directly induced by PCV2 infection (Kim and Chae 2004). The maximum levels of both chemokines were detected before granulomatous inflammation in lymph node of one-day-old piglets inoculated with PCV2 via the intranasal route (Kim and Chae 2004). As MCP-1 and MIP-1 have effective chemoattractant and activating effects on monocytes (Wolpe et al. 1988), high levels of both were speculated to largely facilitate monocyte recruitment from blood. The greater number of monocytes recruited to lymphoid tissues should 
augment and amplify cytokine secretion and cell recruitment, induce granulomatous inflammation, and eventually lead to PCVAD (Fig. 1). In addition to monocytes, MIP-1 has been proposed to be associated with the recruitment of neutrophils (Wolpe et al. 1988; Standiford et al. 1995), which may be the major cause of the aforementioned cell-proportional alterations in lymphoid tissues of PCVAD-affected pigs. These findings indicate that interaction of monocyte/macrophage cell lineages with PCV2 plays an important role in mediating granulomatous lesions in lymph nodes and inducing PCVAD (Fig. 1). Monocytes and macrophages play a crucial role in host immune defense system against virus infection. Revealing the involvement of these cells in PCVAD is important in understanding pathogenesis and host immune response induced by PCV2 infection.

\section{Role of IL-10 in PCV2 infection}

Cytokine profile alteration induced by PCV2 infection played an important role in the pathogenesis of PCVAD. PBMCs from pigs with PMWS displayed a positive response to recall PCV2 antigen stimulation by upregulating of IL-10 and IFN- $\gamma$ expression (Kekarainen et al. $2008 \mathrm{~b}$ ), and scarcely produced IL-4, IL-2, or IFN- $\gamma$ in response to stimulation by mitogen (phytohemagglutinin) or superantigen (Darwich et al. 2003a; Kekarainen et al., 2008a). Further, PCV2 can inhibit IL-2 and IL-4 secretion by PBMCs isolated from both healthy and PMWSaffected pigs (Darwich et al. 2003a), which is proposed to impair and weaken host immune defense against virus infection. IL-10 can impair pathogen eliminating function of cells, including macrophages, Th1 and NK cells, and affect both innate and adaptive immune reactions. PCV2 infection has been demonstrated to promote secretion of IL-10 by PBMCs cultured in vitro, mainly monocytes/macrophages and DCs, which reduce the release of IFN- $\gamma$, IFN- $\alpha$ and IL-12 (Darwich et al. 2003a; Kekarainen et al. 2008a, 2008b; Kekarainen and Segalés 2015). Further, the expression of IL-10 is demonstrated to be upregulated in thymus of pigs with PCVAD, which is proposed to be related to lymphoid depletion, thymic atrophy, and immune dysfunction (Darwich et al. 2003a).

\section{Host humoral and cellular immune responses to PCV2 infection}

In field cases, a proportion of PCV2-infected pigs did not develop PCVAD (Meng 2013). The limitation or elimination of PCV2 infection in these pigs should be related to the development of effective humoral and cellular immune responses, which reflects the significance of host adaptive immune response in counteracting PCV2 infection (Fort et al. 2009; Darwich and Mateu 2012; Meng 2013). Humoral immune response has been suggested to play an important role in the defense process, as the level of neutralizing antibody correlates with viral replication, pathologic lesion severity, and the onset of disease in PCV2-infected pigs (Hangartner et al. 2006; Meerts et al. 2006; Fort et al. 2007; Song et al. 2007). In specific-pathogen-free and gnotobiotic pigs experimentally infected with PCV2, antibodies against PCV2 can be detected at 10 days and 15 days post infection, respectively. The levels of total antibody and neutralizing antibody in PMWS-affected pigs have been shown to be lower than in asymptomatic pigs, and asymptomatic pigs also present early seroconversion (Meerts et al. 2005a, 2006). Besides, anti-PCV2 antibodies passively obtained from sow through the colostrum are effective at protecting newborn piglets. In fact, the higher the maternal antibodies in the piglets, the lower the probability of viremia (McKeown et al. 2005; Ostanello et al. 2005; Saha et al. 2014). The detectable antibody concentration in piglets was proposed to be positively correlated with that observed in the sow (Kekarainen and Segalés 2015). With a decline in the antibody concentration of milk, the susceptibility of piglets to PCV2 infection gradually increases (RodríguezArrioja et al. 2002; Larochelle et al. 2003; Grau-Roma et al. 2009). These findings also reflect that antibodies play an important role in fighting against PCV2 infection.

However, antibodies against PCV2 are not always fully protective. The effective function of neutralizing antibodies against pathogens is markedly dependent on macrophages, which can clear the antigen-antibody complex. PCV2 infection impairs phagocytic and microbicidal ability of macrophages (Chang et al. 2006a, 2006b), which may interfere with the functioning of neutralizing antibodies. Besides, viruses are obligatory intracellular pathogens and PCV2 has evolved to lead a persistent infection in immune cells. Therefore, in addition to humoral immunity, cellular immunity is also of great significance in host defense against PCV2 infection.

Lymphoid depletion is known to be the hallmark feature of PCVAD. However, certain $\mathrm{T}$ cell subsets have also been demonstrated to be downregulated, including naïve $\mathrm{CD} 4^{+} \mathrm{CD} 8^{-} \mathrm{Th}$ cells, $\mathrm{CD} 4^{-} \mathrm{CD} 8^{+}$cytotoxic $\mathrm{T}$ cells, and $\mathrm{CD}^{+}{ }^{+} \mathrm{CD} 4^{+} \mathrm{CD}^{+}$memory/activated $\mathrm{Th}$ cells, in PCVAD (Nielsen et al. 2003). Among these cell subsets, the reduction degree of the latter subset was proposed to correlate with disease development (Nielsen et al. 2003; Kekarainen and Segalés 2015). The level of PCV2specific IFN- $\gamma$ secreting cells (SC) displayed a negative correlation with viral burden, and was demonstrated to be induced upon PCV2 infection and vaccination, along with PCV2 specific IFN- $\gamma /$ TNF- $\alpha$ co-producing CD4+ subsets (Meerts et al. 2005a; Fort et al. 2007, 2008; 
Kekarainen and Segalés 2015). Both IFN- $\gamma / \mathrm{TNF}-\alpha$ coproducing $\mathrm{CD} 4+$ cell subset and IFN- $\gamma$-SC were proposed to play central roles in cellular immune defense against PCV2 infection (Kekarainen and Segalés 2015; Koinig et al. 2015).

As an immunosuppressive virus, PCV2 may serve as an appropriate model for revealing how single-stranded DNA viruses interact with host immune defenses. Understanding and dissecting the underlying mechanisms involved in PCV2 infection and host immune reaction are of great significance for PCVAD prevention and control.

\section{Interaction between PCV3 and host immune system}

In contrast to PCV2, experimental infection with PCV3 alone without immune stimulation by keyhole limpet hemocyanin injection was demonstrated to successfully reproduce PDNS (Jiang et al. 2019a). PCV3 has also been shown to infect lymphoid organs, including lymph nodes and spleen, and PCV3 antigen was reported to be detected in lymphocytes, macrophages, neutrophils, eosinophils and epithelial cells of infected tissues (Palinski et al. 2016; Jiang et al. 2019a). Destruction of lymphoid follicles followed by white pulp atrophy was observed in PCV3-infected spleens. Further, intensive infiltration of eosinophils and hemosiderosis was markedly observed in lymph nodes of PCV3-infected pigs, besides lymphoid depletion and histiocytic infiltration observed in PCV2infected cases (Jiang et al. 2019a). Eosinophils are recognized to play a significant role in mediating inflammatory response to allergen stimulation or pathogen infection, as well as inducing host antiviral immunity. It is speculated that eosinophil infiltration may serve as an important causal factor for allergic inflammatory symptoms, including skin rashes and asthma, and an immunocompromised state in PCV3-infected pigs (Jiang et al. 2019a). Although PCV3 has been shown to reside in eosinophils, whether PCV3 can perform a proliferative replication in cells remains unclear. Interactions between PCV3 and the eosinophils are thus of great significance and warrant further investigation.

Innate immune response has been proven to play an essential role in the fight against PCV3 infection; this was revealed by the upregulation of some of phagocytosis-associated proteins and ISG-encoded proteins induced by PCV3 infection (Jiang et al. 2019b). The expression levels of MHC- I and MHC- II were also significantly upregulated by PCV3 infection, which may promote host adaptive defense by mediating and facilitating the antigen presenting activity and cytotoxic $\mathrm{T}$ cell killing effect (Jiang et al. 2019b).

The role of PCV3 in host immunomodulation and immune injury mechanisms has also been revealed with respect to the following aspects. PBMCs isolated from
PCV3-infected pigs exhibited deficient proliferation capacity in response to mitogen stimulation, which may lead to T lymphocyte anergy (Jiang et al. 2019b). PCV3 Cap protein has been reported to inhibit cellular IFN production induced by the recognition of foreign DNA molecules by interacting with G3BP1, which appears to affect the initiation and activation of host innate and adaptive immune responses (Zhang et al. 2020). Expression of HSP60 was upregulated in response to PCV3 infection, which may interfere with host immune defense and favor viral infection (Jiang et al. 2019b). Hemosiderin is produced by macrophages after phagocytosis of red blood cells. Histopathologic diagnosis of lymph nodes in PCV3-infected pigs revealed abundant hemosiderin deposition (Jiang et al. 2019b), which indicates that vascular damage may be induced by severe inflammation. Besides, the upregulation of proinflammatory cytokines, such as IL-1 $\beta$, IL- 6 and TNF- $\alpha$, and the enhanced levels of acute-phage proteins, including clusterin, ITIH4 and haptoglobin etc. triggered by PCV3 infection may be associated with severe inflammation in affected pigs and may contribute to lymphoid depletion and the subsequent immune destruction (Jiang et al. 2019b).

\section{Conclusions and perspectives}

PCV2 and PCV3 are considered to induce host immune suppression during infection. PCV2 can induce a persistent infection in host and has evolved strategies to exploit and manipulate the immune cells and immune responses for its own benefit. With the successful isolation and propagation of PCV2 in vitro, many studies have been conducted on interactions between PCV2 and host immune system; however, study on PCV3 interactions with host immune system remains sketchy and is still warranted. Although both belongs to the pathogenic porcine circoviruses, there are many differences between PCV2 and PCV3 including their genome size, amino acid sequences of Cap proteins, as well as the ways to establish animal infection models of both. Such finding indicates that there are differences in the performances of PCV2 and PCV3 in the process of immune interactions with host. In addition, cellular surface receptors of PCV2 and PCV3 are speculated to differ (Misinzo et al. 2006; Shi et al. 2021), which may serve as one of the important factors leading to distinct clinical symptoms and host immune response. Therefore, comparative studies between PCV2 and PCV3 infection in vitro and in vivo are warranted to better elucidate the pathogenic mechanisms and immune interactions of PCVs. Furthermore, a detailed analysis on the mechanism of host immune responses to infection with PCV2 and PCV3 will be useful for the development of novel effective vaccines for the control of PCVAD in the future. 


\section{Acknowledgements}

Not applicable.

\section{Authors' contributions}

RS and JL: Conceptualization. RS and LH: Writing-original draft preparation. RS and JL: Writing-review and editing. JL: Supervision and project administration. JL: Funding acquisition. All authors have critically read and edited the manuscript. The author(s) read and approved the final manuscript.

\section{Funding}

This study was supported by a grant from the Priority Academic Program Development of Jiangsu Higher Education Institutions (PAPD).

\section{Availability of data and materials}

Not applicable.

\section{Declarations}

Ethics approval and consent to participate

Not applicable.

\section{Consent for publication}

Not applicable.

\section{Competing interests}

Author Jue Liu was not involved in the journal's review or decisions related to this manuscript.

\section{Author details}

${ }^{1}$ Beijing Key Laboratory for Prevention and Control of Infectious Diseases in Livestock and Poultry, Institute of Animal Husbandry and Veterinary Medicine, Beijing Academy of Agriculture and Forestry Sciences, Beijing 100097, China. ${ }^{2}$ Department of Preventive Veterinary Medicine, College of Veterinary Medicine, Yangzhou University, No. 48 Wenhui Road, Hanjiang District, Yangzhou 225009, China. ${ }^{3}$ Jiangsu Co-Innovation Center for Prevention and Control of Important Animal Infectious Diseases and Zoonoses, Yangzhou University, Yangzhou 225009, China.

Received: 18 August 2021 Accepted: 27 September 2021

\section{Published online: 13 October 2021}

\section{References}

Allan, G.M., and J.A. Ellis. 2000. Porcine circoviruses: A review. Journal of Veterinary Diagnostic Investigation 12 (1): 3-14. https://doi.org/10.1177/1040638700012 00102.

Allan, G.M., S. Kennedy, F. Mcneilly, J.C. Foster, J.A. Ellis, et al. 1999. Experimental reproduction of severe wasting disease by co-infection of pigs with porcine circovirus and porcine parvovirus. Journal of Comparative Pathology 121 (1): 1-11. https://doi.org/10.1053/jcpa.1998.0295.

Allan, G.M., F. Mcneilly, J. Ellis, S. Krakowka, B. Meehan, et al. 2000. Experimental infection of colostrum deprived piglets with porcine circovirus 2 (PCV2) and porcine reproductive and respiratory syndrome virus (PRRSV) potentiates PCV2 replication. Archives of Virology 145 (11): 2421-2429. https://doi.org/10.1 007/s007050070031.

Balmelli, C., E. Steiner, H. Moulin, N. Peduto, and K. Mccullough. 2015. Porcine circovirus type 2 DNA influences cytoskeleton rearrangements in plasmacytoid and monocyte-derived dendritic cells. Immunology 132 (1): 5765. https://doi.org/10.1111/j.1365-2567.2010.03339.X.

Cecere, T.E., X.J. Meng, K. Pelzer, S.M. Todd, N.M. Beach, Y.Y. Ni, and T. Leroith. 2012. Co-infection of porcine dendritic cells with porcine circovirus type $2 a$ (PCV2a) and genotype II porcine reproductive and respiratory syndrome virus (PRRSV) induces CD4(+)CD25(+)FoxP3(+) T cells in vitro. Veterinary Microbiology 160 (1-2): 233-239. https://doi.org/10.1016/j.vetmic.2012.04.040.

Chae, C. 2004. Postweaning multisystemic wasting syndrome: A review of aetiology, diagnosis and pathology. Veterinary Journal 168 (1): 41-49. https:// doi.org/10.1016/j.tvjl.2003.09.018.

Chang, H.W., C.R. Jeng, T.L. Lin, J.J. Liu, M.T. Chiou, Y.C. Tsai, M.Y. Chia, T.R. Jan, and V.F. Pang. 2006a. Immunopathological effects of porcine circovirus type 2 (PCV2) on swine alveolar macrophages by in vitro inoculation. Veterinary Immunology and Immunopathology 110 (3-4): 207-219. https://doi.org/10.101 6/j.vetimm.2005.09.016.
Chang, H.W., V.F. Pang, L.J. Chen, M.Y. Chia, Y.C. Tsai, and C.R. Jeng. 2006b. Bacterial lipopolysaccharide induces porcine circovirus type 2 replication in swine alveolar macrophages. Veterinary Microbiology 115 (4): 311-319. https:// doi.org/10.1016/j.vetmic.2006.03.010.

Chung, H.C., G. Nguyen, Y.H. Park, and B.K. Park. 2021. Genotyping of PCV3 based on reassembled viral gene sequences. Veterinary Medical Science 7 (2): 474482. https://doi.org/10.1002/vms3.374.

Darwich, L., M. Balasch, J. Plana-Durán, J. Segalés, M. Domingo, and E. Mateu. 2003a. Cytokine profiles of peripheral blood mononuclear cells from pigs with postweaning multisystemic wasting syndrome in response to mitogen, superantigen or recall viral antigens. The Journal of General Virology 84 (12): 3453-3457. https://doi.org/10.1099/vir.0.19364-0.

Darwich, L., and E. Mateu. 2012. Immunology of porcine circovirus type 2 (PCV2). Virus Research 164 (1-2): 61-67. https://doi.org/10.1016/j.virusres.2011.12.003.

Darwich, L., S. Pié, A. Rovira, J. Segalés, M. Domingo, I.P. Oswald, and E. Mateu. 2003b. Cytokine mRNA expression profiles in lymphoid tissues of pigs naturally affected by postweaning multisystemic wasting syndrome. The Journal of General Virology 84 (Pt 8): 2117-2125. https://doi.org/10.1099/vir.0.19124-0.

Darwich, L., J. Segalés, M. Domingo, and E. Mateu. 2002. Changes in CD4+, CD8+, CD4+ CD8+, and immunoglobulin M-positive peripheral blood mononuclear cells of postweaning multisystemic wasting syndrome-affected pigs and agematched uninfected wasted and healthy pigs correlate with lesions and porcine circovirus. Clinical and Diagnostic Laboratory Immunology 9 (2): 236242. https://doi.org/10.1128/cdli.9.2.236-242.2002.

Dorr, P.M., R.B. Baker, G.W. Almond, S.R. Wayne, and W.A. Gebreyes. 2007. Epidemiologic assessment of porcine circovirus type 2 coinfection with other pathogens in swine. Journal of the American Veterinary Medical Association 230 (2): 244-250. https://doi.org/10.2460/javma.230.2.244.

Ellis, J. 2014. Porcine circovirus: A historical perspective. Veterinary Pathology 51 (2): 315-327. https://doi.org/10.1177/0300985814521245.

Ellis, J., L. Hassard, E. Clark, J. Harding, G. Allan, P. Willson, J. Strokappe, K. Martin F. McNeilly, B. Meehan, D. Todd, and D. Haines. 1998. Isolation of circovirus from lesions of pigs with postweaning multisystemic wasting syndrome. The Canadian Veterinary Journal 39 (1): 44-51.

Fan, S., X. Ku, F. Chen, Y. Wang, X. Yu, and Q. He. 2016. Complete genome sequence of a novel porcine circovirus type 3 strain, PCV3/CN/Hubei-618/ 2016, isolated from China. Genome Announcements 5 (15): e00100-e00117. https://doi.org/10.1128/genomeA.00100-17.

Fort, M., A. Olvera, M. Sibila, J. Segalés, and E. Mateu. 2007. Detection of neutralizing antibodies in postweaning multisystemic wasting syndrome (PMWS)-affected and non-PMWS-affected pigs. Veterinary Microbiology 125 (3-4): 244-255. https://doi.org/10.1016/j.vetmic.2007.06.004.

Fort, M., M. Sibila, A. Allepuz, E. Mateu, F. Roerink, and J. Segalés. 2008. Porcine circovirus type 2 (PCV2) vaccination of conventional pigs prevents viremia against PCV2 isolates of different genotypes and geographic origins. Vaccine. 26 (8): 1063-1071. https://doi.org/10.1016/j.va ccine.2007.12.019.

Fort, M., M. Sibila, E. Pérez-Martín, M. Nofrarías, E. Mateu, and J. Segalés. 2009. One dose of a porcine circovirus 2 (PCV2) sub-unit vaccine administered to 3-week-old conventional piglets elicits cell-mediated immunity and significantly reduces PCV2 viremia in an experimental model. Vaccine. 27 (30): 4031-4037. https://doi.org/10.1016/j.vaccine.2009.04.028.

Frank, I., M. Piatak Jr., H. Stoessel, N. Romani, D. Bonnyay, J.D. Lifson, and M. Rope. 2002. Infectious and whole inactivated simian immunodeficiency viruses interact similarly with primate dendritic cells (DCs): Differential intracellular fate of virions in mature and immature DCs. Journal of Virology 76 (6): 29362951. https://doi.org/10.1128/jvi.76.6.2936-2951.2002.

Geissmann, F., M.G. Manz, S. Jung, M.H. Sieweke, M. Merad, and K. Ley. 2010. Development of monocytes, macrophages, and dendritic cells. Science. 327 (5966): 656-661. https://doi.org/10.1126/science.1178331.

Gilpin, D.F., K. Mccullough, B.M. Meehan, F. Mcneilly, I. McNair, L.S. Stevenson, J.C. Foster, J.A. Ellis, S. Krakowka, B.M. Adair, and G.M. Allan. 2003. In vitro studies on the infection and replication of porcine circovirus type 2 in cells of the porcine immune system. Veterinary Immunology and Immunopathology 94 (3-4): 149-161. https://doi.org/10.1016/s0165-2427(03)00087-4.

Grau-Roma, L., C.K. Hjulsager, M. Sibila, C.S. Kristensen, S. López-Soria, C. Enøe, J. Casal, A. Bøtner, M. Nofrarías, V. Bille-Hansen, L. Fraile, P. Baekbo, J. Segalés, and L.E. Larsen. 2009. Infection, excretion and seroconversion dynamics of porcine circovirus type 2 (PCV2) in pigs from post-weaning multisystemic wasting syndrome (PMWS) affected farms in Spain and Denmark. Veterinary Microbiology 135 (3-4): 272-282. https://doi.org/10.1016/j.vetmic.2008.10.007. 
Grierson, S.S., D.P. King, A.W. Tucker, M. Donadeu, M.A. Mellencamp, K. Haverson, M. Banks, and M. Bailey. 2007. Ontogeny of systemic cellular immunity in the neonatal pig: Correlation with the development of post-weaning multisystemic wasting syndrome. Veterinary Immunology and Immunopathology 119 (3-4): 254-268. https://doi.org/10.1016/j.vetimm.2007. 06.004.

Ha, Y., Y.H. Lee, K.K. Ahn, B. Kim, and C. Chae. 2008. Reproduction of postweaning multisystemic wasting syndrome in pigs by prenatal porcine circovirus 2 infection and postnatal porcine parvovirus infection or immunostimulation. Veterinary Pathology 45 (6): 842-848. https://doi.org/10.1354/vp.45-6-842.

Hangartner, L., R.M. Zinkernagel, and H. Hengartner. 2006. Antiviral antibody responses: The two extremes of a wide spectrum. Nature Reviews. Immunology 6 (3): 231-243. https://doi.org/10.1038/nri1783.

Harding, J., J. Ellis, D. Todd, B. Meehan, S. Kennedy, C. Charreyre, E. Espuna, E.G. Clark, F. McNeilly, and A. Botner. 1998. Novel porcine circoviruses from pigs with wasting disease syndromes. The Veterinary Record 142 (17): 467-468. https://doi.org/10.1016/S0304-4017(97)00170-2.

Jiang, H., D. Wang, J. Wang, S. Zhu, R. She, X. Ren, J. Tian, R. Quan, L. Hou, Z. Li, J. Chu, Y. Guo, Y. Xi, H. Song, F. Yuan, L. Wei, and J. Liu. 2019a. Induction of porcine dermatitis and nephropathy syndrome in piglets by infection with porcine circovirus type 3. Journal of Virology 93 (4): e02045-e02018. https:// doi.org/10.1128/JVI.02045-18.

Jiang, H., L. Wei, D. Wang, J. Wang, S. Zhu, R. She, T. Liu, J. Tian, R. Quan, L. Hou, Z. Li, J. Chu, J. Zhou, Y. Guo, Y. Xi, H. Song, F. Yuan, and J. Liu. 2019b. ITRAQ based quantitative proteomics reveals the first proteome profiles of piglets infected with porcine circovirus type 3. Journal of Proteomics 212: 103598. https://doi.org/10.1016/j.jprot.2019.103598.

Kekarainen, T., M. Montoya, J. Dominguez, E. Mateu, and J. Segalés. 2008a. Porcine circovirus type 2 (PCV2) viral components immunomodulate recall antigen responses. Veterinary Immunology and Immunopathology 124 (1-2): 41-49. https://doi.org/10.1016/j.vetimm.2008.01.031.

Kekarainen, T., M. Montoya, E. Mateu, and J. Segales. 2008b. Porcine circovirus type 2-induced interleukin-10 modulates recall antigen responses. The Journal of General Virology 89 (3): 760-765. https://doi.org/10.1099/vir.0.83354-0.

Kekarainen, T., and J. Segalés. 2015. Porcine circovirus 2 immunology and viral evolution. Porcine Health Management 1 (1): 17. https://doi.org/10.1186/s4 0813-015-0012-z

Kim, J., and C. Chae. 2004. Expression of monocyte chemoattractant protein-1 and macrophage inflammatory protein-1 in porcine circovirus 2-induced granulomatous inflammation. Journal of Comparative Pathology 131 (2-3): 121-126. https://doi.org/10.1016/j.jcpa.2004.02.001.

Kim, J., C. Choi, and C. Chae. 2003. Pathogenesis of postweaning multisystemic wasting syndrome reproduced by co-infection with Korean isolates of porcine circovirus 2 and porcine parvovirus. Journal of Comparative Pathology 128 (1): 52-59. https://doi.org/10.1053/jcpa.2002.0605.

Kiupel, M., G.W. Stevenson, J. Choi, K.S. Latimer, C.L. Kanitz, and S.K. Mittal. 2001. Viral replication and lesions in BALB/C mice experimentally inoculated with porcine circovirus isolated from a pig with postweaning multisystemic wasting disease. Veterinary Pathology 38 (1): 74-82. https://doi.org/10.1354/vp.38-1-74.

Koinig, H.C., S.C. Talker, M. Stadler, A. Ladinig, R. Graage, M. Ritzmann, I. HennigPauka, W. Gerner, and A. Saalmüller. 2015. PCV2 vaccination induces IFN- $\gamma$ / TNF-a co-producing $T$ cells with a potential role in protection. Veterinary Research 46 (1): 20. https://doi.org/10.1186/s13567-015-0157-4.

Krakowka, S., J.A. Ellis, F. Mcneilly, S. Ringler, D.M. Rings, and G. Allan. 2001. Activation of the immune system is the pivotal event in the production of wasting disease in pigs infected with porcine circovirus-2 (PCV-2). Veterinary Pathology 38 (1): 31-42. https://doi.org/10.1354/vp.38-1-31.

Krakowka, S., J.A. Ellis, B. Meehan, S. Kennedy, F. Mcneilly, and G. Allan. 2000. Viral wasting syndrome of swine: Experimental reproduction of postweaning multisystemic wasting syndrome in gnotobiotic swine by coinfection with porcine circovirus 2 and porcine parvovirus. Veterinary Pathology 37 (3): 254263. https://doi.org/10.1354/vp.37-3-254.

Krakowka, S., C. Hartunian, A. Hamberg, D. Shoup, M. Rings, Y. Zhang, G. Allan, and J.A. Ellis. 2008. Evaluation of induction of porcine dermatitis and nephropathy syndrome in gnotobiotic pigs with negative results for porcine circovirus type 2. American Journal of Veterinary Research 69 (12): 1615-1622. https://doi.org/10.2460/ajvr.69.12.1615.

Larochelle, R., R. Magar, and S. D'Allaire. 2003. Comparative serologic and virologic study of commercial swine herds with and without postweaning multisystemic wasting syndrome. Canadian Journal of Veterinary Research 67 (2): 114-120.
Li, W., S. Liu, Y. Wang, F. Deng, W. Yan, K. Yang, H. Chen, Q. He, C. Charreyre, and J.C. Audoneet. 2013. Transcription analysis of the porcine alveolar macrophage response to porcine circovirus type 2. BMC Genomics 14 (1): 353. https://doi.org/10.1186/1471-2164-14-353.

Liu, J., I. Chen, and J. Kwang. 2005. Characterization of a previously unidentified viral protein in porcine circovirus type 2-infected cells and its role in virusinduced apoptosis. Journal of Virology 79 (13): 8262-8274. https://doi.org/1 0.1128/JVI.79.13.8262-8274.2005.

Liu, S., Q. Li, J. Qiao, J. Wang, D. Cui, K. Gu, S. Zhou, and H. Li. 2019. Endothelial IL8 induced by porcine circovirus type 2 affects dendritic cell maturation and antigen-presenting function. Virology Journal 16 (1): 154. https://doi.org/10.11 86/s12985-019-1256-z.

McKeown, N.E., T. Opriessnig, P. Thomas, D.K. Guenette, F. Elvinger, M. Fenaux, P. G. Halbur, and X.J. Meng. 2005. Effects of porcine circovirus type 2 (PCV2) maternal antibodies on experimental infection of piglets with PCV2. Clinical and Diagnostic Laboratory Immunology 12 (11): 1347-1351. https://doi.org/1 0.1128/CDLI.12.11.1347-1351.2005.

Meerts, P., G. Misinzo, D. Lefebvre, J. Nielsen, A. Bøtner, C.S. Kristensen, and H.J. Nauwynck. 2006. Correlation between the presence of neutralizing antibodies against porcine circovirus 2 (PCV2) and protection against replication of the virus and development of PCV2-associated disease. BMC Veterinary Research 2 (1): 6. https://doi.org/10.1186/1746-6148-2-6.

Meerts, P., G. Misinzo, F. Mcneilly, and H.J. Nauwynck. 2005b. Replication kinetics of different porcine circovirus 2 strains in PK-15 cells, fetal cardiomyocytes and macrophages. Archives of Virology 150 (3): 427-441. https://doi.org/10.1 007/s00705-004-0444-2.

Meerts, P., S. Van Gucht, E. Cox, A. Vandebosch, and H.J. Nauwynck. 2005a. Correlation between type of adaptive immune response against porcine circovirus type 2 and level of virus replication. Viral Immunology 18 (2): 333341. https://doi.org/10.1089/vim.2005.18.333.

Mellman, I., and R.M. Steinman. 2001. Dendritic cells. Cell. 106 (3): 255-258. https://doi.org/10.1016/s0092-8674(01)00449-4.

Meng, X.J. 2013. Porcine circovirus type 2 (PCV2): Pathogenesis and interaction with the immune system. Annual Review of Animal Biosciences 1 (1): 43-64. https://doi.org/10.1146/annurev-animal-031412-103720.

Misinzo, G., P.L. Delputte, P. Meerts, D.J. Lefebvre, and H.J. Nauwynck. 2006. Porcine circovirus 2 uses heparan sulfate and chondroitin sulfate B glycosaminoglycans as receptors for its attachment to host cells. Journal of Virology 80 (7): 3487-3494. https://doi.org/10.1128/JVl.80.7.3487-3494.2006.

Morozov, I., T. Sirinarumitr, S.D. Sorden, P.G. Halbur, M.K. Morgan, K.J. Yoon, and P. S. Paul. 1998. Detection of a novel strain of porcine circovirus in pigs with postweaning multisystemic wasting syndrome. Journal of Clinical Microbiology 36 (9): 2535-2541. https://doi.org/10.1128/JCM.36.9.2535-2541.1 998.

Nielsen, J., I.E. Vincent, A. Bøtner, A.S. Ladekaer-Mikkelsen, G. Allan, A. Summerfield, and K.C. McCullough. 2003. Association of lymphopenia with porcine circovirus type 2 induced postweaning multisystemic wasting syndrome (PMWS). Veterinary Immunology and Immunopathology 92 (3-4): 97-111. https://doi.org/10.1016/s0165-2427(03)00031-x.

Opriessnig, T., M. Fenaux, P. Thomas, M.J. Hoogland, M.F. Rothschild, X.J. Meng, and P.G. Halbur. 2006. Evidence of breed-dependent differences in susceptibility to porcine circovirus type-2-associated disease and lesions. Veterinary Pathology 43 (3): 281-293. https://doi.org/10.1354/vp.43-3-281.

Opriessnig, T., and P.G. Halbur. 2012. Concurrent infections are important for expression of porcine circovirus associated disease. Virus Research 164 (1-2): 20-32. https://doi.org/10.1016/j.virusres.2011.09.014.

Opriessnig, T., X.J. Meng, and P.G. Halbur. 2007. Porcine circovirus type 2 associated disease: Update on current terminology, clinical manifestations, pathogenesis, diagnosis, and intervention strategies. Journal of Veterinary Diagnostic Investigation 19 (6): 591-615. https://doi.org/10.1177/104063 870701900601

Ostanello, F., A. Caprioli, A.D. Francesco, M. Battilani, G. Sala, G. Sarli, L. Mandrioli, F. McNeilly, G.M. Allan, and S. Prosperi. 2005. Experimental infection of 3week-old conventional colostrum-fed pigs with porcine circovirus type 2 and porcine parvovirus. Veterinary Microbiology 108 (3-4): 179-186. https://doi. org/10.1016/j.vetmic.2005.04.010.

Palinski, R., P. Piñeyro, P. Shang, F. Yuan, R. Guo, Y. Fang, E. Byers, and B.M. Hause. 2016. A novel porcine circovirus distantly related to known circoviruses is associated with porcine dermatitis and nephropathy syndrome and reproductive failure. Journal of Virology 91 (1): e01879-e01816. https://doi. org/10.1128/JVI.01879-16. 
Pallares, F.J., P.G. Halbur, T. Opriessnig, S.D. Sorden, D. Villar, B.H. Janke, et al. 2002. Porcine circovirus type 2 (PCV-2) coinfections in US field cases of postweaning multisystemic wasting syndrome (PMWS). Journal of Veterinary Diagnostic Investigation 14 (6): 515-519. https://doi.org/10.1177/104063870201400614.

Ploegh, H.L. 1998. Viral strategies of immune evasion. Science. 280 (5361): 248253. https://doi.org/10.1126/science.280.5361.248.

Ramamoorthy, S., and X.J. Meng. 2009. Porcine circoviruses: A minuscule yet mammoth paradox. Animal Health Research Reviews 10 (1): 1-20. https://doi. org/10.1017/S1466252308001461.

Ren, L., X. Chen, and H. Ouyang. 2016. Interactions of porcine circovirus 2 with its hosts. Virus Genes 52 (4): 437-444. https://doi.org/10.1007/s11262-016-1326-X.

Resendes, A.R., N. Majó, J. Segalés, E. Mateu, M. Calsamiglia, and M. Domingo. 2004. Apoptosis in lymphoid organs of pigs naturally infected by porcine circovirus type 2. The Journal of General Virology 85 (Pt 10): 2837-2844. https://doi.org/10.1099/vir.0.80221-0.

Rodríguez-Arrioja, G.M., J. Segalés, M. Calsamiglia, A.R. Resendes, M. Balasch, J. Plana-Duran, J. Casal, and M. Domingo. 2002. Dynamics of porcine circovirus type 2 infection in a herd of pigs with postweaning multisystemic wasting syndrome. American Journal of Veterinary Research 63 (3): 354-357. https:// doi.org/10.2460/ajvr.2002.63.354.

Rosell, C., J. Segalés, J. Plana-Durán, M. Balasch, G.M. Rodríguez-Arrioja, S. Kennedy, G.M. Allan, F. McNeilly, K.S. Latimer, and M. Domingo. 1999. Pathological, immunohistochemical, and in-situ hybridization studies of natural cases of postweaning multisystemic wasting syndrome (PMWS) in pigs. Journal of Comparative Pathology 120 (1): 59-78. https://doi.org/10.1 053/jcpa.1998.0258.

Saha, D., R.D.P. Sacristán, N. Van Renne, L. Huang, R. Decaluwe, A. Michiels, et al. 2014. Anti-porcine circovirus type 2 (PCV2) antibody placental barrier leakage from sow to fetus: Impact on the diagnosis of intra-uterine PCV2 infection. Virologica Sinica 29 (2): 136-138. https://doi.org/10.1007/s12250-014-3432-z.

Segalés, J., G.M. Allan, and M. Domingo. 2005. Porcine circovirus diseases. Animal Health Research Reviews 6 (2): 119-142. https://doi.org/10.1079/ahr2005106.

Shen, H., X. Liu, P. Zhang, L. Wang, Y. Liu, L. Zhang, P. Liang, and C. Song. 2017. Genome characterization of a porcine circovirus type 3 in South China. Transboundary and Emerging Diseases 65 (1): 1-3. https://doi.org/10.1111/ tbed.12639.

Shi, R., L. Hou, L. Wei, R. Quan, B. Zhou, H. Jiang, J. Wang, S. Zhu, J. Song, D. Wang, and J. Liu. 2021. Porcine circovirus type 3 enters into PK15 cells through clathrin- and dynamin-2-mediated endocytosis in a Rab5/Rab7 and pH-dependent fashion. Frontiers in Microbiology 12: 636307. https://doi.org/1 0.3389/fmicb.2021.636307.

Shibahara, T., K. Sato, Y. Ishikawa, and K. Kadota. 2000. Porcine circovirus induces B lymphocyte depletion in pigs with wasting disease syndrome. The Journal of Veterinary Medical Science 62 (11): 1125-1131. https://doi.org/10.1292/jvms.62.1125.

Sipos, W., J.C. Duvigneau, M. Willheim, F. Schilcher, R.T. Hartl, G. Hofbauer, B. Exel, P. Pietschmann, and F. Schmoll. 2004. Systemic cytokine profile in feeder pigs suffering from natural postweaning multisystemic wasting syndrome (PMWS) as determined by semiquantitative RT-PCR and flow cytometric intracellular cytokine detection. Veterinary Immunology and Immunopathology 99 (1-2): 63-71. https://doi.org/10.1016/j.vetimm.2004.01.001.

Song, Y., M. Jin, S. Zhang, X. Xu, S. Xiao, S. Cao, and H. Chen. 2007. Generation and immunogenicity of a recombinant pseudorabies virus expressing cap protein of porcine circovirus type 2. Veterinary Microbiology 119 (2-4): $97-$ 104. https://doi.org/10.1016/j.vetmic.2006.08.026.

Standiford, T.J., S.L. Kunkel, N.W. Lukacs, M.J. Greenberger, J.M. Danforth, R.G. Kunkel, and R.M. Strieter. 1995. Macrophage inflammatory protein-1 alpha mediates lung leukocyte recruitment, lung capillary leak, and early mortality in murine endotoxemia. Journal of Immunology 155 (3): 1515-1524.

Tochetto, C., D.A. de Lima, A.P.M. Varela, L.C. Ortiz, M.R. Loiko, C.M. Scheffer, W.P. Paim, S.P. Cibulski, C. Cerva, J. Herpich, C. Schmidt, A.C. Franco, F.Q. Mayer, and P.M. Roehe. 2020. Investigation on porcine circovirus type 3 in serum of farrowing sows with stillbirths. Microbial Pathogenesis 149: 104316. https:// doi.org/10.1016/j.micpath.2020.104316.

Vincent, I.E., C. Balmelli, B. Meehan, G. Allan, A. Summerfield, and K.C. McCullough. 2006. Silencing of natural interferon producing cell activation by porcine circovirus type 2 DNA. Immunology 120 (1): 47-56. https://doi.org/10.1111/ j.1365-2567.2006.02476.x.

Vincent, I.E., C.P. Carrasco, L. Guzylack-Piriou, B. Herrmann, F. McNeilly, G.M. Allan, A. Summerfield, and K.C. McCullough. 2005. Subset-dependent modulation of dendritic cell activity by circovirus type 2. Immunology 115 (3): 388-398. https://doi.org/10.1111/j.1365-2567.2005.02165.x.
Vincent, I.E., C.P. Carrasco, B. Herrmann, B.M. Meehan, G.M. Allan, A. Summerfield, and K.C. McCullough. 2003. Dendritic cells harbor infectious porcine circovirus type 2 in the absence of apparent cell modulation or replication of the virus. Journal of Virology 77 (24): 13288-13300. https://doi.org/10.1128/jvi. 77.24.13288-13300.2003

Wang, X., L. Chen, W. Yuan, Y. Li, L. Li, T. Li, H. Li, and Q. Song. 2017. Effect of porcine circovirus type 2 (PCV2) on the function of splenic CD11c+ dendritic cells in mice. Archives of Virology 162 (5): 1289-1298. https://doi.org/10.1007/ s00705-017-3221-8.

Wolpe, S.D., G. Davatelis, B. Sherry, B. Beutler, D.G. Hesse, H.T. Nguyen, L.L. Moldawer, C.F. Nathan, S.F. Lowry, and A. Cerami. 1988. Macrophages secrete a novel heparin-binding protein with inflammatory and neutrophil chemokinetic properties. The Journal of Experimental Medicine 167 (2): 570 581. https://doi.org/10.1084/jem.167.2.570.

Yu, S., T. Opriessnig, P. Kitikoon, D. Nilubol, P.G. Halbur, and E. Thacker. 2007a. Porcine circovirus type 2 (PCV2) distribution and replication in tissues and immune cells in early infected pigs. Veterinary Immunology and Immunopathology 115 (3-4): 261-272. https://doi.org/10.1016/j.vetimm.2 006.11 .006$.

Yu, S., A. Vincent, T. Opriessnig, S. Carpenter, P. Kitikoon, P.G. Halbur, and E. Thacker. 2007b. Quantification of PCV2 capsid transcript in peripheral blood mononuclear cells (PBMCs) in vitro. Veterinary Microbiology 123 (1-3): 34-42. https://doi.org/10.1016/j.vetmic.2007.02.021.

Zhai, S., X. Zhou, H. Zhang, B. Hause, T. Lin, R. Liu, Q. Chen, W. Wei, D. Lv, X. Wen, F. Li, and D. Wang. 2017. Comparative epidemiology of porcine circovirus type 3 in pigs with different clinical presentations. Virology Journal 14 (1): 222. https://doi.org/10.1186/s12985-017-0892-4.

Zhang, P., H. Shen, X. Liu, S. Wang, Y. Liu, Z. Xu, and C. Song. 2020. Porcine circovirus type 3 cap inhibits type I interferon induction through interaction with G3BP1. Frontiers in Veterinary Science 7: 594438. https://doi.org/10.3389/ fvets.2020.594438.

Zhu, B., Y. Zhou, F. Xu, J. Shuai, X. Li, and W. Fang. 2012. Porcine circovirus type 2 induces autophagy via the AMPK/ERKTSC2/mTOR signaling pathway in PK15 cells. Journal of Virology 86 (22): 12003-12012. https://doi.org/10.1128/JVI. 01434-12.

\section{Publisher's Note}

Springer Nature remains neutral with regard to jurisdictional claims in published maps and institutional affiliations.

Ready to submit your research? Choose BMC and benefit from:

- fast, convenient online submission

- thorough peer review by experienced researchers in your field

- rapid publication on acceptance

- support for research data, including large and complex data types

- gold Open Access which fosters wider collaboration and increased citations

- maximum visibility for your research: over $100 \mathrm{M}$ website views per year

At BMC, research is always in progress.

Learn more biomedcentral.com/submissions 